\title{
Craving for heroin: difference between methadone maintenance therapy patients with and without ADHD
}

\author{
Fissura por heroína: diferença entre pacientes em terapia de manutenção com \\ metadona com e sem TDAH
}

Maurizio Coppola, ${ }^{1}$ (D) Giuseppe Sacchetto, ${ }^{1}$ Raffaella Mondola ${ }^{2}$

\begin{abstract}
Introduction: Attention deficit hyperactivity disorder (ADHD) is a neurodevelopmental disorder persisting in adulthood in $40-60 \%$ of cases. Clinical and neuroimaging studies suggest that patients affected by both drug addiction and ADHD show higher rates of craving for drug than patients without ADHD. We designed a pilot open-label study to investigate the effects of ADHD on craving for heroin in methadone maintenance therapy patients.

Method: Patients were recruited from outpatient facilities in an addiction treatment unit in the municipality of Alba, Italy. They were assessed using the Structured Clinical Interview for DSM-5 (SCID-5), the SCID-5 for Personality Disorders (SCID-5-PD), the Diagnostic Interview for Adult ADHD, second edition (DIVA 2.0), and the Clinical Opiate Withdrawal Scale (COWS). Categorical variables were examined using the chi-square test, and continuous variables, the t-test and Mann-Whitney's $U$ test for normally and non-normally distributed data, respectively. Data distribution was evaluated using Shapiro-Wilk's test. Significance was set at $p=0.05$. Bonferroni correction was applied (0.0063) to avoid type I error.

Results: A total of 104 patients were included in the study: 14 affected by ADHD (13.5\%) and 90 were not affected (86.5\%). Patients with ADHD showed higher intensity of craving for heroin than patients without ADHD in the absence of withdrawal symptoms.

Conclusion: Drug addiction and ADHD share various neurobiological mechanisms that mutually influence the evolution of both disorders. In particular, dopamine dysfunction within various brain circuits may influence impulsivity levels, motivation, inhibitory control, executive functions, and behavior and, consequently, the intensity of craving.
\end{abstract}

Keywords: Craving, addiction, ADHD, heroin.

\section{Resumo}

Introdução: $O$ transtorno de déficit de atenção e hiperatividade (TDAH) é um transtorno do neurodesenvolvimento que persiste na idade adulta em 40-60\% dos casos. Estudos clínicos e de neuroimagem sugerem que pacientes afetados tanto por adição quanto por TDAH apresentam maiores índices de fissura (craving) por droga do que pacientes sem TDAH. Este estudo piloto aberto investigou os efeitos do TDAH sobre fissura por heroína em pacientes em terapia de manutenção com metadona.

Método: Os pacientes foram recrutados em serviços ambulatoriais em uma unidade de tratamento de adição na cidade de Alba, Itália. Eles foram avaliados usando os seguintes instrumentos: Structured Clinical Interview for DSM-5 (SCID5), SCID-5 for Personality Disorders (SCID-5-PD), Diagnostic Interview for Adult TDAH, second edition (DIVA 2.0) e Clinical Opiate Withdrawal Scale (COWS). Variáveis categóricas foram examinadas utilizando o teste do qui-quadrado, e variáveis contínuas, o teste t e o teste $\mathrm{U}$ de Mann-Whitney para dados com distribuição normal e não normal, respectivamente. A distribuição dos dados foi avaliada usando o teste de Shapiro-Wilk. O nível de significância foi estabelecido em $p=0,05$. A correção de Bonferroni foi aplicada $(0,0063)$ para evitar erro tipo I.

Resultados: Um total de 104 pacientes foram incluídos no estudo: 14 com TDAH (13,5\%) e 90 sem $(86,5 \%)$. Pacientes com TDAH mostraram maior intensidade de fissura por heroína do que pacientes sem TDAH na ausência de sintomas de abstinência.

Conclusão: Adição e TDAH compartilham mecanismos neurobiológicos que influenciam mutuamente a evolução dos dois transtornos. Em particular, a disfunção da dopamina em vários circuitos cerebrais pode influenciar os níveis de impulsividade, motivação, controle inibitório, funções executivas e comportamento, e, portanto, a intensidade da fissura.

Descritores: Fissura, adição, TDAH, heroína.

\footnotetext{
${ }^{1}$ Dipartimento Dipendenze, ASL CN2, Alba, CN, Italy. ${ }^{2}$ Dipartimento Salute Mentale, ASL CN1, Saluzzo, CN, Italy. Submitted Dec 28 2017, accepted for publication Aug 062018.

Suggested citation: Coppola M, Sacchetto G, Mondola R. Craving for heroin: difference between methadone maintenance therapy patients with and without ADHD. Trends Psychiatry Psychother. 2019;41(1):83-86. http://dx.doi.org/10.1590/2237-6089-2017-0159
} 


\section{Introduction}

Attention deficit hyperactivity disorder (ADHD) is a neurodevelopmental disorder persisting in adulthood in $40-60 \%$ of cases. ${ }^{1}$ Clinically, it is characterized by symptoms of hyperactivity, impulsivity and inattention, but in adults, symptoms can change in intensity, modality of presentation and clinical characteristics. ${ }^{1}$ In particular, inattention may be replaced with difficulty in carrying out tasks and hyperactivity may be replaced with restless, anxiety and irritability. ${ }^{2,3}$ ADHD is considered a risk factor for developing substance abuse as well as a clinical condition influencing duration, severity and remission rates of addiction. ${ }^{4}$ Moreover, clinical and neuroimaging studies suggest that patients affected by both drug addiction and ADHD show higher rates of craving for drug than patients without ADHD. ${ }^{5,6}$

Correlation between ADHD and substance abuse can be justified by various factors, including neurobiological mechanisms and clinical aspects. Research evidence suggests that patients affected by ADHD show dysfunction within multiple neuronal circuits, including neuronal networks involved in the regulation of the reward system. ${ }^{4,7}$ These neurobiological alterations appear to be similar to those present in patients affected by substance abuse. ${ }^{4,7}$ Additionally, ADHD patients frequently show psychiatric comorbidities, such as mood and anxiety disorders, increasing the risk of drug abuse. ${ }^{8}$ Finally, ADHD symptoms, in particular impulsivity, are themselves risk factors for substance abuse. .,10 $^{2}$

The present pilot open-label study was designed to investigate the effects of ADHD on craving for heroin in methadone maintenance therapy patients. Our hypothesis was that patients with ADHD would show stronger craving than patients without ADHD. In line with this hypothesis, we also evaluated the difference between patients with and without ADHD in clinical parameters correlated with severity of craving, such as the dose of methadone to achieve abstinence from heroin and the consumption of other drugs.

\section{Method}

Our work was a pilot open-label study carried out from January to June 2016. Patients were recruited from outpatient facilities in an addiction treatment unit in the municipality of Alba, Italy. All included patients signed a written informed consent form, and the study was conducted in accordance with the Declaration of Helsinki. Our data were extracted from the study approved by the local ethics committee (protocol ASLCN2).
Inclusion criteria were: 1) being 18 years old or older; 2) having a diagnosis of heroin dependence in accordance with criteria from the Diagnostic and Statistical Manual of Mental Disorders, 5th edition (DSM$5)$, as assessed by the Structured Clinical Interview for DSM-5 (SCID-5) ${ }^{11}$; 3) having no alcohol dependence in accordance with the DSM-5, as assessed by the SCID$5 ; 4)$ urine screening tests resulting negative for opioids in the past 30 days; 5) pharmacological treatment with methadone and absence of withdrawal symptoms as assessed by the Clinical Opiate Withdrawal Scale $(\text { COWS })^{12}$ (scale score <5). ADHD was assessed using the structured Diagnostic Interview for Adult ADHD, second edition (DIVA 2.0), ${ }^{13}$ personality disorders were assessed using the SCID-5 for Personality Disorders (SCID-5-PD), ${ }^{14}$ and craving for heroin was assessed using a visual analogue scale (VAS). ${ }^{15}$ In patients affected by ADHD, clinical assessment was performed before starting pharmacological treatment for ADHD symptoms. Patients included in our study had not ever received pharmacological treatment for ADHD.

Data were examined using Social Science Statistics resources (www.socscistatistics.com/). Sociodemographic and clinical characteristics were reported as mean and standard deviation or absolute number (\%). Categorical variables were examined using the chi-square test, while continuous variables were examined using the t-test and the Mann-Whitney $U$ test for normally and non-normally distributed data, respectively. Normal or non-normal distribution of variables was evaluated using the Shapiro-Wilk test. A p-value of 0.05 was considered significant. Bonferroni correction was applied (0.0063) to avoid type I error.

\section{Results}

A total of 104 patients were included in the study (Table 1): 14 were affected by ADHD (13.5\%), while 90 were not affected (86.5\%). No difference between the groups was found in sociodemographic characteristics. In particular, no difference was found in age, sex, education, marital status or employment. Patients with ADHD showed higher rates of comorbidity with other drugs of abuse than patients without ADHD.

In particular, $57 \%$ of the patients with ADHD showed urine screening tests positive for cannabis and/or cocaine, while only $15 \%$ of the patients without ADHD had positive results for these drugs. However, it is important to specify that these results lost significance after Bonferroni correction was applied. Differently, no differences were found between the groups in terms of comorbidity with other psychiatric disorders, 
including personality disorders. The group with ADHD showed significantly higher VAS scores than the group without ADHD, evidencing stronger craving for heroin among patients with ADHD if compared with those without ADHD. Finally, statistical analysis found that patients with ADHD were stabilized at higher dosages of methadone than patients without ADHD.

\section{Discussion}

In this pilot open-label study, differences in the intensity of craving for heroin were evaluated in methadone maintenance therapy patients with and without ADHD. We used a VAS score as an appropriate tool to quantify the craving for heroin, in particular the dimension of intensity of desire. ${ }^{16,17}$ In order to exclude the effect on craving produced by withdrawal symptoms, we included in our study only patients in methadone maintenance therapy (COWS score $<5$ ).

In our sample, $13.5 \%$ of the patients were diagnosed with ADHD, a percentage substantially lower than that reported in epidemiological studies. ${ }^{18}$ No difference between patients with and without ADHD was found in age, sex, education, marital status or employment. In line with currently available literature data, the sample affected by ADHD showed polydrug abuse more frequently than the sample without ADHD. ${ }^{19}$ However, when Bonferroni correction was applied to our data, this result lost significance. Our consideration to partially justify the effect of Bonferroni correction is that the small size of our sample played a key role in minimizing the correlation between ADHD and substance abuse, producing a result in obvious contrast with the scientific literature.

Differently from epidemiological data, ${ }^{1}$ our results revealed no differences between the groups in terms of comorbidity with psychiatric disorders, including personality disorders. Also this result may be the result of bias due to the small size of our sample. As clearly shown in Table 1 , patients with ADHD had higher intensity of craving than patients without ADHD. Moreover, patients with ADHD required significantly higher methadone dosages to inhibit withdrawal symptoms than patients without ADHD.

Drug addiction and ADHD share various neurobiological mechanisms that mutually influence

Table 1 - Comparison in sociodemographic and clinical characteristics between patients with and without ADHD

\begin{tabular}{|c|c|c|c|}
\hline & ADHD $(n=14)$ & No ADHD $(n=90)$ & $\mathbf{p}$ \\
\hline \multicolumn{4}{|l|}{ Sex } \\
\hline Male & 9 & 72 & 0.63 \\
\hline Female & 5 & 18 & 0.31 \\
\hline Age, mean \pm SD & $38.79 \pm 7.81$ & $40.68 \pm 9.16$ & 0.46 \\
\hline Education (years) & 8 & 8.5 & 0.86 \\
\hline \multicolumn{4}{|l|}{ Marital status } \\
\hline Single & 9 & 49 & 0.71 \\
\hline Married/cohabiting & 5 & 36 & 0.83 \\
\hline Separated or divorced & 0 & 5 & 0.82 \\
\hline \multicolumn{4}{|l|}{ Employment status } \\
\hline Employed & 5 & 48 & 0.46 \\
\hline Not employed & 9 & 42 & 0.49 \\
\hline \multicolumn{4}{|l|}{ Comorbidity } \\
\hline Psychiatric disorders & 8 & 43 & 0.63 \\
\hline Abuse of other drugs & 8 & 14 & $0.010 *$ \\
\hline VAS score, mean \pm SD & $6.66 \pm 0.54$ & $5.83 \pm 1.03$ & 0.0043 \\
\hline MTD dosage (milligrams), mean \pm SD & $75 \pm 6.92$ & $66.71 \pm 10.09$ & 0.0038 \\
\hline
\end{tabular}

Data presented as $n$, unless otherwise specified.

$\mathrm{ADHD}=$ attention deficit hyperactivity disorder; $\mathrm{MTD}=$ methadone; $\mathrm{SD}=$ standard deviation.

* Not significant following Bonferroni correction. 
the evolution of both disorders. In particular, dopamine dysfunction within the nucleus accumbens, orbitofrontal cortex, anterior cingulate gyrus, dorsolateral prefrontal cortex, amygdala, dorsal striatum, and ventral pallidum may influence impulsivity levels, motivation, inhibitory control, executive functions, and behavior - and, consequently, the intensity of craving. ${ }^{20,21}$ Substance abuse and ADHD may also mutually influence morbidity and mortality in these patients, as comorbid substance use disorder and ADHD have accounted for the highest mortality rate ratios across all disruptive behavior disorders, suggesting that a high level of attention is required in the management of these disorders. ${ }^{22}$

In conclusion, despite the limitations related with both small sample size and study design (open-label), our results have shown that: 1 ) ADHD was associated with higher intensity of heroin craving; 2) ADHD patients needed high doses of methadone. On the whole, the findings show association between presence of ADHD and both intensity of craving and doses of methadone, but further research is needed to evaluate the causality behind these associations. Physicians should consider this psychiatric disorder in patients affected by heroin addiction, because ADHD could influence severity of addiction, response to pharmacological treatments and long-term outcomes.

\section{Disclosure}

No conflicts of interest declared concerning the publication of this article.

\section{References}

1. Volkow ND, Swanson JM. Adult attention deficit-hyperactivity disorder. N Engl J Med. 2013;369:1935-44.

2. Wender $\mathrm{PH}$. Attention deficit-hyperactivity disorder in adults. Psychiatr Clin North Am. 1988;21:761-74.

3. Faraone SV, Biederman J, Mick E. The age-dependent decline of attention deficit hyperactivity disorder: a meta-analysis of follow up studies. Psychol Med. 2006;36:159-65.

4. Wilens TE, Biederman J, Mick E. Does ADHD affect the course of substance abuse? Findings from a sample of adults with and without ADHD. Am J Addict. 1998; 7:156-63.

5. Gholamalinezhad F, Abdolmanafi A, Rostami R, Farhoodi F. Comparison of craving in substance use patients with the history of ADHD and substance use without ADHD history. Procedia Soc Behav Sci. 2010;5:17135.
6. Frodl T. Comorbidity of ADHD and substance use disorder (SUD): a neuroimaging perspective. ] Atten Disord. 2010;14:109-20.

7. Volkow ND, Wang GJ, Kollins $\mathrm{SH}$, Wigal TL, Newcorn JH, Telang $F$, et al. Evaluating dopamine reward pathway in ADHD. JAMA. 2009;302:1084-91.

8. Zulauf CA, Sprich SE, Safren SA, Wilens TE. The complicated relationship between attention deficit/hyperactivity disorder and substance use disorders. Curr Psychiatry Rep. 2014;16:436.

9. Oshri A, Kogan SM, Kwon JA, Wickrama KAS, Vanderbroek L, Palmer AA, et al. Impulsivity as a mechanism linking child abuse and neglect with substance use in adolescence and adulthood. Dev Psychopathol. 2017;30:417-35.

10. Gipson CD, Beckmann JS, Adams ZW, Marusich JA, Nesland TO, Yates JR, et al. A translational behavioral model of mood-based impulsivity: Implications for substance abuse. Drug Alcohol Depend. 2012;122:93-9.

11. First MB, Williams JWB, Karg RS, Spitzer RL. Structured Clinical Interview for DSM-5® Disorders--Clinician Version (SCID-5-CV). Washington: American Psychiatric Association Publishing; 2016.

12. Wesson DR, Ling W. The Clinical Opiate Withdrawal Scale (COWS). J Psychoactive Drugs. 2003;35:253-9.

13. Ramos-Quiroga JA, Nasillo V, Richarte V, Corrales M, Palma $F$ Ibáñez $P$, et al. Criteria and concurrent validity of DIVA 2.0: a semi-structured diagnostic interview for adult ADHD. J Atten Disord. 2016 Apr 28. pii: 1087054716646451. [Epub ahead of print]

14. First MB, Williams JWB, Karg RS, Spitzer RL. Structured Clinical Interview for DSM-5 ${ }^{\circledR}$ Personality Disorders (SCID-5-PD). Washington: American Psychiatric Association Publishing; 2016.

15. Hassani-Abharian $P$, Ganjgahi $H$, Tabatabaei-Jafari $H$, Oghabian MA, Mokri A, Ekhtiari H. Exploring neural correlates of different dimensions in drug craving self-reports among heroin dependents. Basic Clin Neurosci. 2015;6:271-84.

16. Falcato L, Beck T, Reimer J, Verthein U. Self-reported cravings for heroin and cocaine during maintenance treatment with slowrelease oral morphine compared with methadone: a randomized, crossover clinical trial. J Clin Psychopharmacol. 2015;35:150-7.

17. Zhao M, Fan $C$, Du J, Jiang $H$, Chen $H$, Sun $H$. Cue-induced craving and physiological reactions in recently and long-abstinent heroindependent patients. Addict Behav. 2012;37:393-8.

18. van Emmerik-van Oortmerssena $K$, van de Glindc $G$, van den Brinkb W, Smitc F, Crunelle CL, Swetsa M, et al. Prevalence of attention-deficit hyperactivity disorder in substance use disorder patients: A meta-analysis and meta-regression analysis. Drug Alcohol Depend. 2012;122:11-9.

19. Stein MT. ADHD: The diagnostic process from different perspectives. J Dev Behav Pediatr. 2004;25:S54-8.

20. Regnart J, Truter I, Meyer A. Critical exploration of co-occurring attention-deficit/hyperactivity disorder, mood disorder and substance use disorder. Expert Rev Pharmacoecon Outcomes Res. 2017; 17:275-82.

21. Volkowa ND, Wangc GJ, Fowlerc JS, Tomasib D, Telangb F. Addiction: beyond dopamine reward circuitry. PANS. 2011;108:15037-42.

22. Scott JG, Giørtz Pedersen M, Erskine HE, Bikic A, Demontis D, McGrath JJ, et al. Mortality in individuals with disruptive behavior disorders diagnosed by specialist services - A nationwide cohort study. Psychiatry Res. 2017;251:255-60.

\section{Correspondence:}

Maurizio Coppola

Dipartimento Dipendenze, ASL CN2

Corso Coppino 46

12051 - Alba, CN - Italy

Tel.: +39 0173316210 , Fax: +39017335067

E-mail: coppolamail@alice.it 